\title{
Development of a Pilot-scale Pulse Electric Field system for Processing Liquid Foods
}

\author{
Oluremilekun Oyetunji ${ }^{1}$, Opeyemi Adeagbo ${ }^{1}$, Faruq Quadri ${ }^{1}$, Felix Ishola ${ }^{2}$, Angela Mamudu ${ }^{3}$, \\ Eniola Akinbode ${ }^{3,4}$, \\ ${ }^{1}$ Department of Mechanical Engineering, Ladoke Akintola University of Technology, Nigeria, \\ oroyetunji@lautech.edu.ng \\ ${ }^{2}$ Department of Mechanical Engineering, Covenant University, Nigeria, dayoishola@ gmail.com \\ ${ }^{3}$ Department of Chemical Engineering, Covenant University, Nigeria, angiestone765@ gmail.com \\ ${ }^{4}$ Department of Microbiology, University of Ibadan, Nigeria, eniolatomisin@ gmail.com
}

\begin{abstract}
Pulse-Electric Field (PEF) System can be described as a system that utilises high voltages applied at a specific interval and with a particular wave shape in treatment (inactivation and destruction of micro-organism cells) of liquid or solid food. Pulse-Electric Field food processing system reduces the drawbacks (such as deterioration in sensory values, energy contents, and freshness) of other methods significantly. To generate the high voltage needed for the treatment, a series of capacitors and diodes connected were used. Generation of the desired pulse shape, which is the square wave is achieved through ATmega-328 microcontroller. The pulse control system is made up of a button to vary the treatment time, the power switch and a 16x2 alphanumeric Liquid Crystal Display (LCD) which serves as visual feedback. For the evaluation of the fabricated system, bacteria were cultured using MacConkey agar solution and then diluted in orange juice which serves as samples of liquid food. From the samples prepared, the bacteria count is in order of $1.61 \times 10^{5} \mathrm{CFU} / \mathrm{mL}$ before treatment, after treatment the count reduced to 1.01 $\mathrm{x} 10^{5} \mathrm{CFU} / \mathrm{mL}$ and $2.10 \times 10^{4} \mathrm{CFU} / \mathrm{mL}$ concerning $1 \mathrm{kHz}$ and $2 \mathrm{kHz}$ pulse frequency used for the two samples treated.
\end{abstract}

Keywords: Pulse-Electric Field, Food Preservation, Square wave, Field Intensity, Design.

\section{INTRODUCTION}

Food is referred to as any substance that can be consumed to provide the body with nutrients [1]. In general, it contains essential nutrients such as proteins, fats, carbohydrates, vitamins and minerals, usually sourced from plants and animals [2]. An organism, including man, ingests food in order to acquire vitality, stimulate growth and sustain life [3]. Foods are purposely consumed for gratification as well as for medicinal reasons to cure ar prevent ailments [4]. While food production has received a high level of attention from researchers and policymakers in addressing food security and sustainability issues, but less related to food processing and preservation [3].
Food handling and logistics widely include growing, harvesting, processing, packaging and distributing food [5]. Foods, except for those that can be consumed in its raw form, are processed from raw forms to ready-to-consume forms. These procedures invariably affect the chemical, physical, and shelf life properties of food [6]. Some of the transformations initiated by food processing are desired. The food shelf life is extended by inactivating the microorganisms, thus improving its aroma, texture, and taste, thereby making the food more appealing and aiding digestion [6]. Moreso, food processing can also cause side effects that can bring unwanted changes in the sensory, physicochemical, and nutritional properties of food contents. Traditionally food processes are classified into thermal (baking, freezing, pasteurization, refrigeration,) [7], nonthermal (pressure treatment, microwave, refining) and mechanical (cutting, peeling, mixing, trimming) [6]. Some of these techniques are also applied commercially for food processing and preservations of packaged foods [8]. While the mechanical process may not be appropriate for liquid foods, thermal methods can cause losses of useful critical nutrients in them [9]. Today, chemical preservatives are administered in the form of food additives to aid the preservation process of liquid foods [10]. However, there is increasing pressure on food manufacturers to avoid the use of such additives entirely or to adopt "natural" alternatives [11]. Moreso, the non-thermal processing techniques have been found very appropriate for liquid food [12].

The non-thermal food processing techniques mainly includes the high hydrostatic pressure application and the pulsed electric field(PEF)amongst others[13][14][15]. Over the years, PEF has proven to be a viable alternative for the processing and preservation of liquid foods such as fruit juices, dairies and liquid eggs [16][17][18]. However, this technique is a method to prolongs the shelf life of liquid foods, but it is costly to set up industrially [19][20]. This project involves the design and development of a pilot-scale cost-effective PEF system using theCockcroft-Walton voltage multiplier application [21]. The research will engender breakthroughs in developing industrial techniques for sustainable and safe liquid food processing in Nigeria. 


\section{EXPERIMENTATION}

A pilot-scale PEF treatment has been designed and built.

\subsection{Hardware Design}

Figure 1 shows the developed block diagram for the designed PEF system. The following components are present in PEF system: (i) High Voltage Pulse Generator (HVPG),

ii) Continuous flow processing chamber, and

iii) Measuring device.

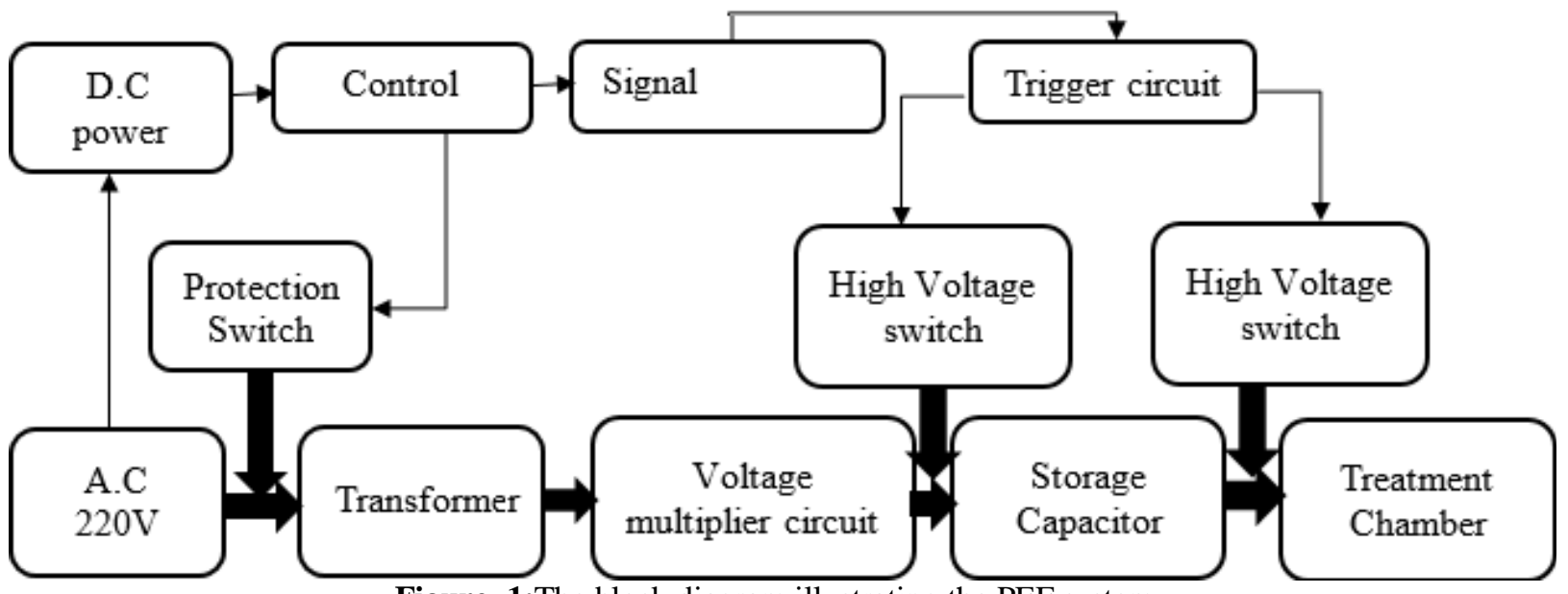

Figure. 1:The block diagram illustrating the PEF system

\subsection{High Voltage Pulse Generator (HVPG)}

HPVG components consist of High Voltage DC Power Supply (HVDC),Switch (S), High Voltage Switch (HVS), Signal Generator (SG), and Capacitor Storage (SC). Figure 2 shows the design of the HVPG electrical circuit. The transformer uses Cockcroft Walton (CW) voltage multiplier tubes to increase the grid voltage from 220 VAC to 400 VAC and from $400 \mathrm{VAC}$ to $5500 \mathrm{VDC}$. The input voltage of the voltage multiplier is taken from the secondary side of the single-phase transformer (220 VAC). A 14-stage cascade was built for the $\mathrm{CW}$ voltage multiplier, each stage containing two capacitors and two diodes. The main components used to build a voltage multiplier circuit are a voltage converter, a series of $1000 \mu \mathrm{F} / 600 \mathrm{~V}$ single capacitance series smoothing capacitors, a series of coupling capacitors and a series of power rectifying diodes $600 \mathrm{~V} / 40$ 1N1190A. It consists of connections

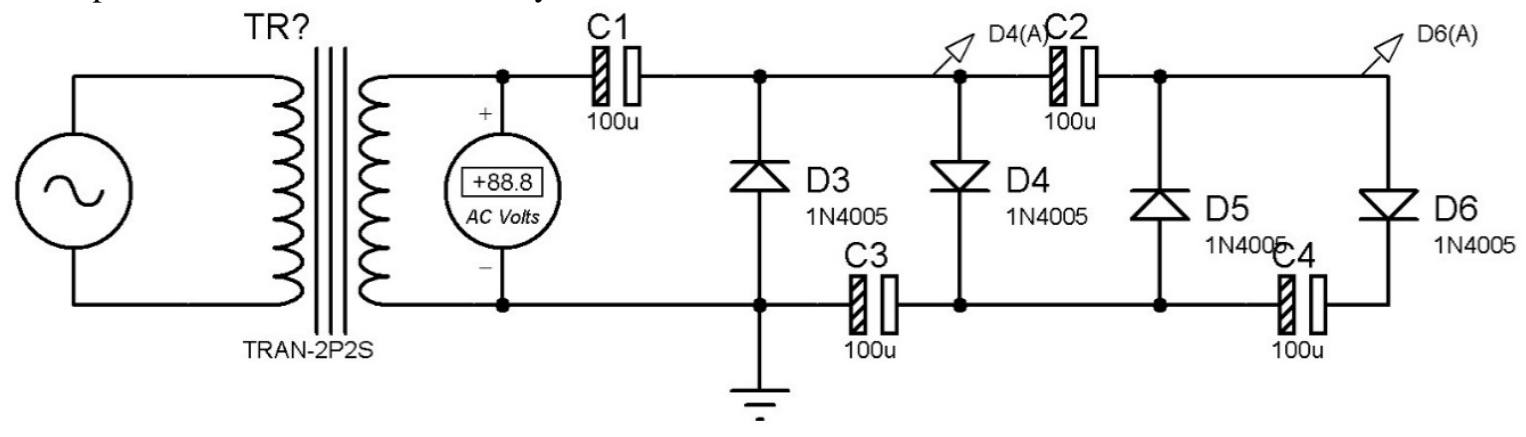

Figure 2:A typical HVPG Electrical circuit diagram

The voltage multiplier circuit uses HVS to charge the storage capacitor $(\mathrm{C})$ in DC format until the preset voltage is reached. The capacitor voltage is converted into narrow pulses in the processing chamber by activating the signal using another HVS and a pulse generator (SG). The DC signal $(5 \mathrm{~V})$ is initiated using an ATmega328P function generation microcontroller. The Microchip ATmega328P is a microcontroller board that operates on an open source Arduino software[22]. These installed DC signals defines the frequency and width of the pulse of the developed PEF systems. The capacitors are built in the system using parallel and series capacitors having capacitance totaling into $6.8 \mu \mathrm{F} / 10 \mathrm{kV}$.

\subsection{Cockcroft-Walton (CW) Voltage multiplier}

Voltage multipliers are a circuit that boosts low voltage alternating current (AC) to high voltage direct current (DC), usually utilsing a combination of a diode and a capacitor[21]. The circuit combines the Villard voltage doubler and the half-wave rectification circuit to obtain a high voltage direct current (DC).The equation that governs the circuit is given below:

$V_{o}=a_{i} \times N \quad, \quad$ [23]

$V_{o}=$ output Voltage

$a_{i}=$ input voltage

$N=$ number of stages 


\subsection{Design Calculations for the Transformer}

For the design of power transformer required for stepping up line voltage from $220 \mathrm{~V}$ to $400 \mathrm{~V}$, the following calculation will be considered.

Output Voltage, $V_{o}=400 \mathrm{~V}$

Output Current, $I_{o}=1$ Amps

Apparent Power Output, $P_{a}\left(V_{o} \times I_{o}\right)=400 \mathrm{Va}$

To determine the true output power of the transformer, a power loss factor of 0.8 (considering that the voltage and current are out of phase by $53^{\circ}$ )

True Power Output, $P_{t}=500 \mathrm{~W}$

Area of transformer needed, $A=\sqrt{P_{t}}$, [24]

$A=\sqrt{500}$

$A=22.36 \mathrm{~cm}^{2}$

$A=\operatorname{Stack}(S) \times$ Tongue $(T)$

Tongue $=5.3 \mathrm{~cm}$

Stack Needed, $S=\frac{22.36}{5.3}$

$S=4.22 \mathrm{~cm}$

The stack is the thickness of the magnetic iron core stacked on each other.

The tongue is the length of the magnetic iron core that house the transformer coil.

\subsubsection{Turns/Volt Calculation}

$E=4.44 f N B_{m} A$, [25]

$E=$ Electro - motive Force $(E . M . F)$

$f=$ oscillating frequency

$B_{m}=$ Electromagnetic induction

$A=$ area of transformer

From the E.M.F equation, turns/volt can be written as,

Turns/volt $\left(\frac{N}{E}\right)=\frac{1}{4.44 f B_{m} A}$

If, $f=50 \mathrm{~Hz}$ (frequency of power transmission in

Nigeria)

$B_{m}=0.9$ (for magnetic iron core)

turns/ volt $=\frac{50.05}{A}$

Turns $/$ Volt $=2.238$

i.e, 2.238 turns will give 1 volt

2.4.2 Calculation Involving Numbers of Turns

On the primary side,

numbers of turns $=2.238 \times 220=492$ turns

On the secondary side,

numbers of turns $=2.238 \times 400=895$ turns

\subsubsection{Wire Guage Determination}

On the primary side,

Current flowing $=\frac{500}{220}=2.27$ amps

Considering the current rating, Guage 16 (Standard Wire

Guage) will be used

On the secondary side,

Current flowing $=\frac{500}{400}=1.25$ amps

Considering the current ratingabove, Guage 20 (Standard

Wire Guage) will be used

\subsection{Electrical Measurements}

The intensity of the electric field $(\mathrm{E}, \mathrm{kV} / \mathrm{cm})$ is calculated as a function of the separation distance $(\mathrm{cm})$ between the parallel electrodes of the processing chamber and the high voltage of the processing chamber during the measurement of PEF processing $(\mathrm{V}, \mathrm{kV})$. The following formula:

$E=\frac{V}{d}$

[15].

$E=$ electric field intensity

$\mathrm{V}=$ Voltage across the chamber during the PEF treatment.

$d=$ distance between two electrode of treatment chamber.

Other parameters measured are:

* Waveform (shape),

* Pulse duration (t, $\mu \mathrm{s})$,

* Pulse rate $(\mathrm{Hz})$

* Current (I, A) across the treatment chamber.

\subsection{Treatment Chamber}

A static processing chamber detains a sizable quantity of the liquid food inside during pulsation and transfer the high voltage pulse to the PEF. The continuous flow processing chamber consists of a $10 \mathrm{~mm}$ diameter tube with two parallel copper electrodes. Figure 3 shows the profile of the flow of the liquid food.

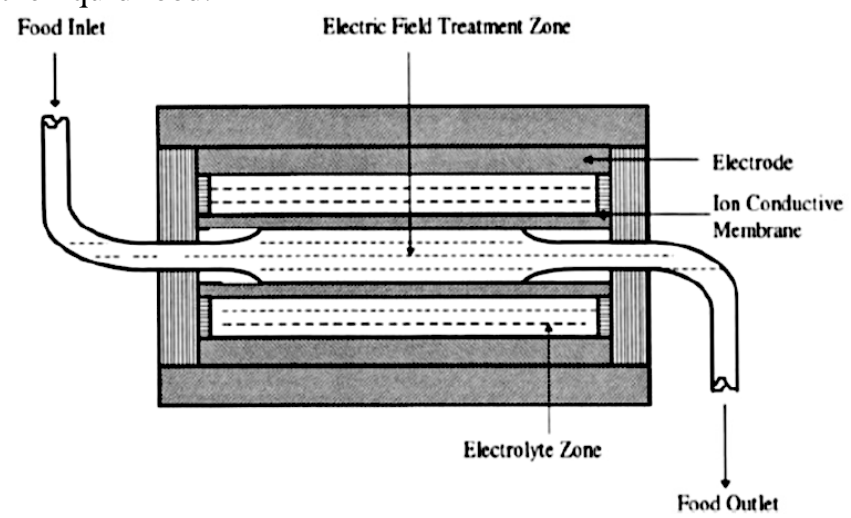

Figure 3: A typical PEF showing the profile of the continuous flow of liquid food through the electric field Chamber[21]

\section{RESULTS AND DISCUSSIONS}

The followings are the recorded results under different categories of the design, fabrication and testing of the pilot scale equipment.

\subsection{Material Selection}

The objective of any design dealing with manufacturing of products is to produce components that will adequately perform the desired task and meeting the objectives the product is design.The performance of the signal generator was also evaluated. Figures 4 and 5 shows the build high voltage generator for the PEF system. A series of tests and changes were made to improve performance and meet desired requirements.

\subsection{Fabrication}

The fabrication of the Pulse-Electric Field System required careful selection of different material and mechanism to produce the desired effect from the system. 


\subsubsection{High Voltage Generation}

In the generation of high voltage, a series of capacitors interlaced with diode was used. The line voltage enters at one side of the circuit, and the very high voltage in the magnitude of $5.5 \mathrm{kV}$ comes out at the other end.

\subsubsection{Pulse Control}

The ATmega-328 was used to achieve control of the pulse. The code which generates the square waveform was written on the Arduino platform. Also, a button input on the microcontroller controls the pulse rates. The pulse rates generated for this project are:

$$
\begin{aligned}
& \text { * } \quad 0 \mathrm{~Hz} \text { at } 5.5 \mathrm{kV} \text {, } \\
& \text { * } 2 \mathrm{~Hz} \text { at } 5.5 \mathrm{kV} \\
& 5.5 \mathrm{kV}
\end{aligned}
$$

The effect of high voltages at various pulse rates is tested.For the feedback and display, a 16x2 alphanumeric Liquid Crystal Display (LCD) connected to the microcontroller and used similar to[26]. A power switch was also used to power on and off the pulse control system.

\subsubsection{Insulation}

The Pulse System was embedded in a plastic casing which prevents the high voltage circuit from the reach of the user. Also, a relay was used in the system to isolate the high voltage side from the output terminal for safety purpose.

\subsection{Liquid Load Testing}

The table 1 shows the properties of the cultured solution used in the testing of liquid food.

Table 1: Bacterial Culture Description

\begin{tabular}{ll}
\hline Micro-organism culture & Bacteria \\
\hline Genus & Escherichia \\
Specie & E.coli \\
Strain & Harmless \\
Growth & MacConkey agar \\
composition & \\
Growth temperature & $44.5^{\circ} \mathrm{C}$ \\
Incubation time & 24 hours \\
\hline
\end{tabular}

\subsubsection{Description of the Procedure for Enumerating Micro-organisms}

\section{Sample Collection}

$1 \mathrm{~L}$ water sample of the gutter was scooped and placed into a sterile grease-free container and then capped.

\section{Laboratory Analysis}

A $100 \mathrm{ml}$ water sample or a dilution of the eluate was mixed with sodium chloride, log-phase host bacteria, and tryptic soy agar with double strength. The sample mixture was incubated at $36^{\circ} \mathrm{C}$ for $16-24$ hours. Counting and summation of circular lysis zones (plaques) were carried out over all plates in each sample. The amount of coliphage in each sample expressed as colony forming units (CFU/ml) per millilitre. Sample analysis of bacterial indicators for E. coli, enter ococci, and faecal E. coli was done by preparing serial dilutions for plating using standard membrane filters. MacConkey agar was used for E. coli. MacConkey agar plates were incubated at a temperature $35^{\circ} \mathrm{C}$ for 2 hours and then at a temperature $44.5^{\circ} \mathrm{C}$ for 22 hours. Pink colonies

\begin{tabular}{|c|c|c|}
\hline & Sample 1 & Sample 2 \\
\hline Voltage(V) & $5500 \mathrm{~V}$ & $5500 \mathrm{~V}$ \\
\hline Current(A) & $1.25 \mathrm{~A}$ & $1.25 \mathrm{~A}$ \\
\hline Electric & $11 \mathrm{kV} / \mathrm{cm}$ & $11 \mathrm{kV} / \mathrm{cm}$ \\
\hline Strength(E) & & \\
\hline Number of pulses & 120 & 60 \\
\hline Pulse Shape & Square & Square \\
\hline Pulse Control Time & $0.5 \mu \mathrm{sec}$ & $1 \mathrm{sec}$ \\
\hline Frequency & $1 \mathrm{kHz}$ & $2 \mathrm{kHz}$ \\
\hline
\end{tabular}
were counted as E. coli.

Table 2: Processing Parameters for Treated Samples

The samples are treated with the parameters listed in the table 2 , and the result is presented in table 3 .

Table 3: Result of the Treated Samples

\begin{tabular}{lcll}
\hline & $\begin{array}{c}\text { Untreated } \\
\text { Sample }\end{array}$ & Sample 1 & Sample 2 \\
\cline { 2 - 4 } Bacteria & $1.61 \times 10^{5}$ & 1.01 & 2.10 \\
Count $(\mathrm{CFU} / \mathrm{mL})$ & & $\times 10^{5}$ & $\times 10^{4}$ \\
\hline
\end{tabular}

The result above shows that there is a reduction in bacteria count when the samples are treated with the Pulse-Electric Field System.Furthermore, it is noticed that the effect of the high voltage varies with the pulse rate. This can be affirmed by comparing the result of sample one (treated at $1 \mathrm{kHz}$ pulse rate) and sample two (treated at $2 \mathrm{kHz}$ pulse rate). For sample one, the bacterial count reduced by $32.27 \%$ compared to sample two with $87 \%$ reduction in bacterial count.

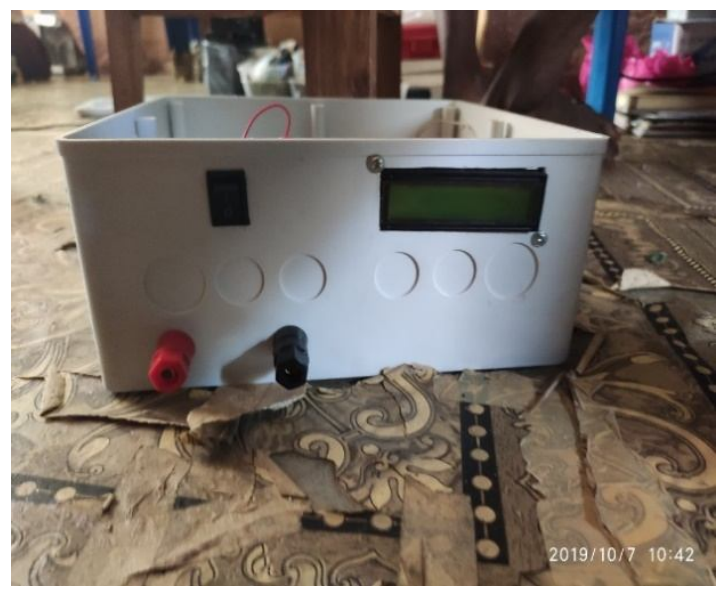

Figure 4: Pulse Generator Front View 


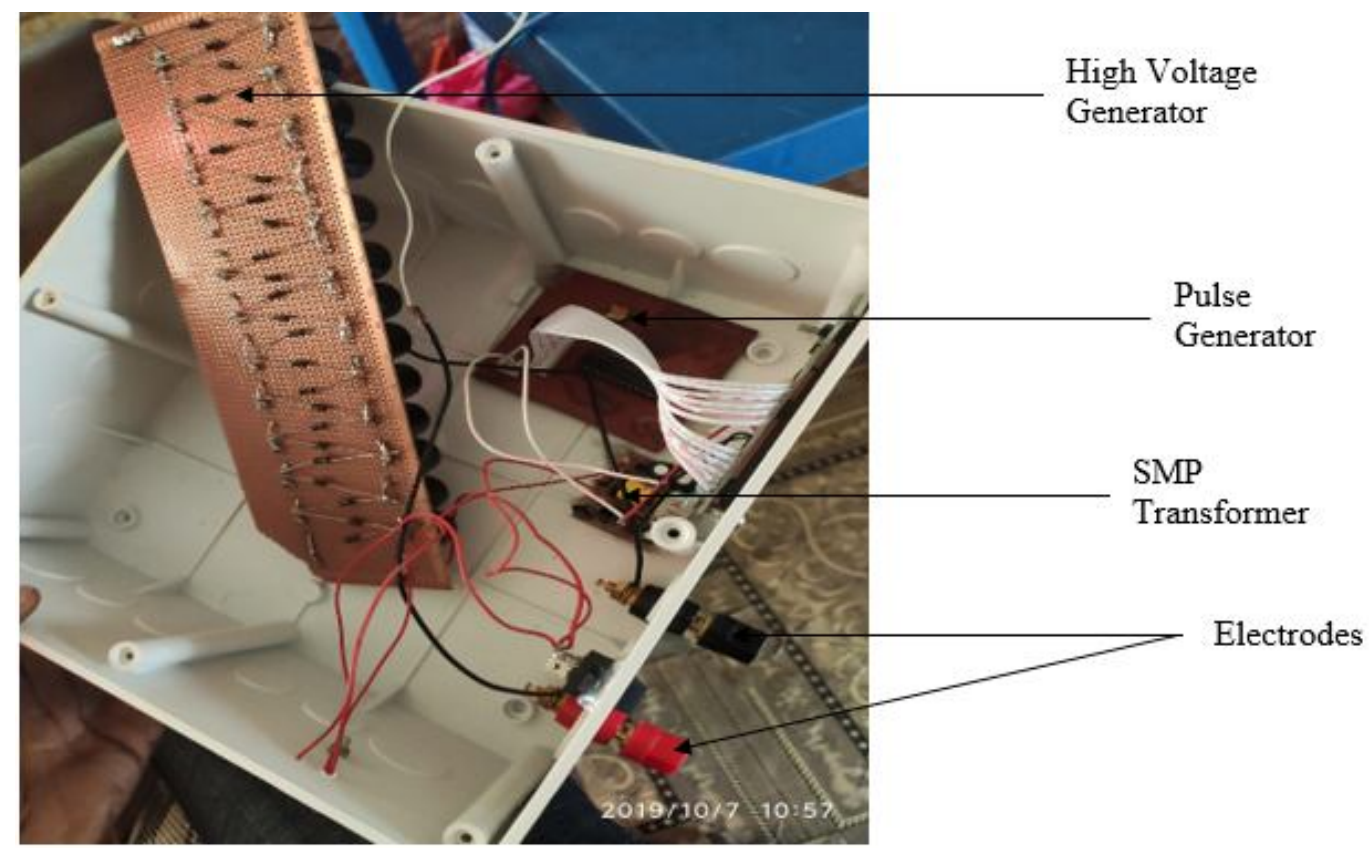

Figure 5: Pulse Generator Inside View

\section{CONCLUSION}

The objectives of this project for the preservation and pretreatment of liquid food were achieved with a reduced size pulse generation system. The result showed that the low-cost fabricated system reduces the activities of microorganism on the treated liquid food samples. The design can be blown up to an industrial scale for a sustainable costeffective liquid food technology in Nigeria.

\section{Acknowledgements}

The author wishes to thank, New biology laboratory, microbiology section, Ladoke Akintola University of Technology for their support for the success of this research, and also Luminous Empire technologies for its contributions. Also, for Covenant University for APC payment.

\section{REFERENCES}

[1] M. Pal and M. Devrani, Application of Various Techniques for Meat Preservation, J. Exp. Food Chem., vol. 4, no. 1, 2018. https://doi.org/10.4172/2472-0542.1000134 H. A. Abdulmumeen, A. N. Risikat, and A. R. Sururah, Food: Its preservatives, additives and applications, Int. J. Chem. Biochem. Sci., vol. 1, pp. 36-47, 2012.

[3] S. T. Hammond et al., Food Spoilage, Storage, and Transport: Implications for a Sustainable Future, Bioscience, vol. 65, no. 8, pp. 758-768, 2015.

[4] P. Putnik, B. Pavli, B. Šoji, L. Kao, and D. Kitoni, Innovative Hurdle Technologies for the Preservation of Functional Fruit Juices, Foods, vol. 9, no. 699, pp. 1-36, 2020.

https://doi.org/10.3390/foods9060699
[5] S. K. Amit, M. Uddin, R. Rahman, S. M. R. Islam, and $M$. S. Khan, A review on mechanisms and commercial aspects of food preservation and processing, Agric. Food Secur., vol. 6, no. 51, pp. $1-22,2017$.

[6] F. Al-juhaimi et al., Effect of various food processing and handling methods on preservation of natural antioxidants in fruits and vegetables, $J$. Food Sci. Technol., vol. 55, no. 10, 2018.

[7] K. O. Babaremu, T. A. Adekanye, I. P. Okokpujie, J. Fayomi, and O. E. Atiba, The Significance of Active Evaporative Cooling System in the Shelf Life Enhancement of Vegetables (Red and Green Tomatoes) for Minimizing Post-Harvest Losses, Procedia Manuf., vol. 35, pp. 1256-1261, 2019. https://doi.org/10.1016/j.promfg.2019.06.084

[8] T. T. Borishade, O. Ogunnaike, J. F. Dirisu, and P. Onochie, Empirical study of packaging and its effect on consumer purchase decision in a food and beverages firm, Eur. J. Bus. Soc. Sci., vol. 3, no. 11, pp. 44-53, 2015.

[9] F. J. Barba et al., Current applications and new opportunities for the use of pulsed electric fields in food science and industry, Food Res. Int., vol. 77, pp. 773-798, 2015.

[10] J. E. Inetianbor, J. M. Yakubu, and E. C. Stephen, Effects of Food Additives and Preservatives on Man - A Review, Asain J. Sci. Technol., vol. 6, no. 2, pp. 1118-1135, 2015.

[11] Y. Kourkoutas and C. Proestos, Food Preservation: Challenges and Efforts for the Future, Foods, vol. 9, no. 391, pp. 1-2, 2020. https://doi.org/10.3390/foods9040391

[12] S. R. Alkhafaji and M. Farid, An investigation on pulsed electric fields technology using new treatment chamber design, Innov. Food Sci. 
Emerg. Technol., vol. 8, pp. 205-212, 2007.

[13] E. Agcam, A. Akyıldiz, and G. A. Evrendilek, Comparison of phenolic compounds of orange juice processed by pulsed electric fields (PEF) and conventional thermal pasteurisation, Food Chem., vol. 143, pp. 354-361, 2014.

[14] S. Toepfl, C. Siemer, G. Saldan a-Navarro, and V. Heinz, Overview of Pulsed Electric Fields Processing for Food, in Emerging Technologies for Food Processing, Quakenbrueck, Germany: Elsevier Ltd., 2014, pp. 93-114.

[15] M. E. Mohamed and A. H. A. Eissa., Pulsed electric fields for food processing technology, in Structure and function of food engineering, 2012, pp. 275306.

[16] B. G. Swanson and G. V Barbosa-canovas, Inactivation of Listeria innocua in skim milk by pulsed electric fields and nisin, Int. J. Food Microbiol., vol. 51, pp. 19-30, 1999.

[17] Laetitia Picart, E. Dumay, and J. C. Cheftel, Inactivation of Listeria innocua in dairy fluids by pulsed electric fields: Influence of electric parameters and food composition, Innov. Food Sci. Emerg. Technol., vol. 3, pp. 357-369, 2002.

[18] Q. A. Syed, A. Ishaq, U. U. Rahman, S. Aslam, and R. Shukat, Pulsed electric field technology in food preservation : a review, J. Nutr. Heal. Food Eng. Res., vol. 6, no. 6, pp. 168-172, 2017. https://doi.org/10.15406/jnhfe.2017.06.00219

[19] S. Jeyamkondan, D. S. Jayas, and R. A. Holley, Pulsed Electric Field Processing of Foods: A Review, J. Food Prot., vol. 62, no. 9, pp. 10881096, 1999.

[20] G. Pataro, G. M. J. Barca, G. Donsì, and G. Ferrari, On the modelling of the electrochemical phenomena at the electrode- solution interface of a PEF treatment chamber: Effect of electrical parameters and chemical composition of model liquid food, J. Food Eng., vol. 165, pp. 45-51, 2015.

[21] S. A. Z. Murad, N. A. Azmi, A. Harun, and T. Z. A. Zulkifli, A Novel 1.6 Kv High Voltage Low Current Step-Up Dc-Dc Converter With Cockcroft-Walton Voltage Multiplier For Power Supply Modules, J. Teknol., vol. 81, no. 5, pp. 113119, 2019.

https://doi.org/10.11113/jt.v81.13411

[22] M. M. Zainuri, N. Han, M. Kamari, A. A. Ibrahim, and N. F. Abdul-Rahman, Development of Standalone PV Led Light System using Adruino, Int. J. Adv. Trends Comput. Sci. Eng., vol. 9, no. 1.2, 2020 .

https://doi.org/10.30534/ijatcse/2020/2291.22020

[23] A. K. Sinha and R. Kumar, Generation Of High Voltage Using Cockcroft-Walton Voltage Multiplier Circuit, Int. Res. J. Eng. Technol., vol. 5, no. 1, pp. 510-513, 2018.

[24] M. C. Sharma, Designing coils and transformers. New Delhi: BPB Publishers, 2007.

[25] B. . Theraja, A Textbook of Electrical Technology -
Transmission and Distribution, vol. 3. Chand (S.) \& Co Ltd, 2007.

[26] E. C. Abana, C. Llamelo, T. B. Daña, R. I. I. I. Cafugauan, N. Angelo, and A. C. Maramag, BMI Assessment Machine with Recommended Ideal Weight, Int. J. Adv. Trends Comput. Sci. Eng., vol. 9, no. 3, pp. 4163-4167, 2020.

https://doi.org/10.30534/ijatcse/2020/247932020 